\title{
Nocturnal intermittent hemodialysis
}

\author{
Julia Thumfart • Dominik Müller
}

Received: 8 April 2014 /Revised: 23 May 2014 / Accepted: 27 May 2014 / Published online: 8 August 2014

(C) IPNA 2014

\begin{abstract}
Preemptive renal transplantation is the method of choice for end stage renal disease in childhood and adolescence. However, without preemptive transplantation, waiting time for kidney transplantation might exceed several years. The poor quality of life and the extremely high morbidity and mortality rates of dialysis patients have led to the development of intensified hemodialysis programs in which the modes of dialysis (short daily, nocturnal intermittent or daily nocturnal) are different. Such programs have been shown to significantly improve several uremia-associated parameters, such as blood pressure, phosphate control, anemia and growth retardation, in both adult and pediatric (children and adolescents) patients and lead to a reduction in medications, including phosphate binders, erythropoietin and antihypertensive agents. Fluid limitations and dietary restrictions can also be lifted. With respect to psychosocial rehabilitation and quality of life, nocturnal intermittent dialysis programs provide a reasonable compromise of all forms of intensified programs. Experiences and practical approaches of our own in-center nocturnal intermittent hemodialysis program in the light of the recent publications are described in this review.
\end{abstract}

Keywords Intensified hemodialysis · Intermittent nocturnal hemodialysis $\cdot$ Hemodiafiltration $\cdot$ Children $\cdot$ Adolescents . Adults

\section{Introduction}

The method of choice for end-stage renal disease (ESRD) in children and adolescents is renal transplantation. However, if

J. Thumfart $\cdot$ D. Müller $(\bowtie)$

Department of Pediatric Nephrology, Charité, Augustenburger

Platz 1, 13353 Berlin, Germany

e-mail: dominik.mueller@charite.de preemptive transplantation is not possible, the average time on the waiting list currently exceeds 2 years in the Eurotransplant region [1].

This time can be even longer if additional factors, such as a high degree of alloimmunization, aggravate the situation. Patients with chronic kidney diseases (CKD) are at high risk for cardiovascular comorbidities and even death. [2, 3]. In children and adolescents receiving renal replacement therapy (RRT), mortality rates are 30-fold higher than those of healthy controls [4]. Expectation of life is dependent on the type of RRT. In 2008 the annual mortality rate in the USA was 0.31 per 1,000 patient years in children and adolescents, whereas the mortality rate in children and adolescents after renal transplantation was 3.5 per 1,000 patient-years; this rose to 36 per 1,000 patient-years in dialysis patients aged $<18$ years [5].

Alterations to the vascular system have been shown to be responsible for the high morbidity and mortality rates in CKD patients $[6,7]$. Uremic vasculopathy progresses during the higher stages of CKD (and dialysis). Whether these alterations to the vascular system are at least partially reversible after renal transplantation remains uncertain. Therefore, it would appear to be appropriate to consider time on dialysis not only as a simple bridging period to transplantation. Consequently, dialysis modalities should be improved to provide a more adequate therapy to attenuate medical and social consequences of ESRD.

Hemodialysis (HD) and peritoneal dialysis (PD), are common dialysis modalities among pediatric patients (children and adolescents). PD is for obvious reasons the method of choice in younger children, while older children and adolescents mostly prefer HD. In this review we focus on HD.

Conventional HD is performed for 4-5 h 3 times per week. In pediatric dialysis patients, CKD-associated comorbidities, such as renal osteopathy, malnutrition, growth retardation and insufficient weight gain, are poorly controlled. Growth retardation rate is correlated with time on dialysis, at least for 
conventional HD. Conventional dialysis programs are unable to reduce these complications [8-10] as illustrated by the fact that conventional forms of dialysis generate a clearance of about $10 \mathrm{ml} / \mathrm{min}$ for small molecules; this clearance may be even less for larger molecules. This means that dialysis only keeps up to the level at which it was initiated. Most dialysis patients have to follow a strict renal diet, including fluid restriction, even when taking medications like phosphate and potassium binders [11].

Social rehabilitation and quality of life of pediatric dialysis patients are poor [12]. Full-time school attendance is only possible every other day - if at all. Even though teachers are present in the dialysis unit, only part of the educational curriculum can be provided and the social environment of school is missing. These circumstances are major factors contributing to the poor quality of life of patients on conventional dialysis treatment, and serious efforts have been made to ameliorate this situation.

The Hemodialysis Study group (HEMO) has shown that neither a modest increase of $\mathrm{Kt} / \mathrm{V}$ nor the use of high-flux filters are able to reduce the mortality rates of adult HD patients on conventional dialysis [13]. Similar results have been shown for adult patients on PD [14]. This deficiency in conventional HD has led to efforts being made to develop intensified HD programs through the use of hemodiafiltration (HDF). The benefit of HDF is that it adds convective HD flow to conventional HD flow, resulting in a more efficient removal of middle-sized molecules [e.g. $\beta 2$-microglobulin ( $\beta 2-\mathrm{MG})$ ] and improved hemodynamic intradialytic stability, possibly by the effect of cooling. Whether HDF reduces mortality is currently a matter of debate. The CONTRAST [15] and the Turkish online hemodiafiltration study [16] have both shown no difference in mortality between HD and online HDF in adult patients. However, patients, who received a convective volume of $>151$ (CONTRAST) or 17.41 (Turkish online hemodiafiltration study), had a significantly lower mortality rate. This result was confirmed in the ESHOL study, where patients on online HDF had a $30 \%$ lower risk of all-cause mortality [17]. However, a review of the $\beta 2-M G$ levels in these studies (CONTRAST: decrease, Turkish online: unchanged, ESHOL: increase) suggests that it is unlikely that the effect of online HDF on mortality is attributable to the removal of middle molecules only.

In contrast, the DOPPS (Dialysis Outcomes and Practice Patterns Study) showed that longer time on dialysis, while urea elimination $(\mathrm{Kt} / \mathrm{V})$ is stable, is associated with a reduction of mortality. In this study, the risk of mortality was significantly reduced when the duration of the dialysis session exceeded $4 \mathrm{~h}$; each $30 \mathrm{~min}$ extension of dialysis reduced the mortality risk by about $7 \%$ [18].

For these and other reasons, focus has been centered on increasing the total dialysis time, which has resulted in the development of the so-called intensified hemodialysis programs.

\section{Intensified HD programs}

First reports on intensified HD programs appeared some 40 years ago, when such an approach was established by Guy Laurent in Tassin, France [19]. In this study, patients were treated with a long, slow HD (24-30 h per week) and then followed up for 10 years. The term 'slow' refers to the fact that blood flow was set to submaximal values. Blood pressure control was achieved by a strict maintenance of dry weight (supplemented with a low salt diet, but without the use of any antihypertensive medication). Overall survival rate was, unprecedented even today, $85 \%$ after 10 years.

Beginning in the late $1990 \mathrm{~s}$, an increasing number of reports on intensified dialysis programs have appeared. Intensification of HD is achieved by either increasing the length (duration of time on HD ( $>5 \mathrm{~h} / \mathrm{session})$ or the frequency ( $>4$ times/week), or both. Basically, there are three different modalities of intensified dialysis programs: short daily hemodialysis (2-3 h per day, 5-7 days per week), nocturnal intermittent hemodialysis ( $8 \mathrm{~h}$ per day, 3 days per week) and daily nocturnal hemodialysis (6-8 h per day, 5-7 days per week). These different programs can be conducted either at home or at the (inor outpatient) dialysis center. In the pediatric setting, short daily HD (SDHD) and nocturnal intermittent HD (NIHD) are performed in the dialysis center or at home; daily nocturnal HD is conducted at home as nocturnal home HD (NHHD) [20].

All these different forms of intensified HD increase the $\mathrm{Kt} / \mathrm{V}$ considerably. Weekly single-pool Kt/V with intensified programs is $4.5-9$, whereas weekly single-pool $\mathrm{Kt} / \mathrm{V}$ with conventional dialysis is 3.6-4 [21]. Moreover, intensified dialysis programs increase not only the $\mathrm{Kt} / \mathrm{V}$ but also the clearance of middle-sized molecules, simply due to the longer duration of the dialysis. The ultrafiltration rate per hour of intensified HD programs can be lowered compared to those of conventional dialysis, thus making this approach especially attractive for unstable patients with cardiovascular conditions. In adult patients on conventional HD, it has been shown that high ultrafiltration rates are associated with a higher mortality even if the dialysis session is well tolerated by the patient [22]. Movilli et al. demonstrated that patients who died within 5 years after the initiation of dialysis had higher ultrafiltration rates than patients who survived ( $14.1 \mathrm{vs.} 11.4 \mathrm{ml} / \mathrm{h} / \mathrm{kg}$ body weight) [22].

The "International Quotidian Dialysis Register" collects data on patients on forms of intensified dialysis [20]. The aim of this register is to analyze outcome in a large cohort of patients under different forms of intensified dialysis. "The Frequent Hemodialysis Network Trial Group," which has published two randomized controlled trials (RCTs) on intensified HD has its origin in this register $[23,24]$. 


\section{Studies in adults on NIHD}

Nocturnal intermittent HD is performed three times weekly, with each session lasting at least $6-8 \mathrm{~h}$, either in-center or at home. Time per session is increased while the frequency of conventional HD is maintained. To date, no randomized controlled prospective trials on NIHD have been conducted. In their prospective, case-controlled study, Ok et al. compared 247 patients on in-center NIHD with 247 patients on conventional HD [25]. In a retrospective study, Lacson et al. compared 746 patients on in-center NIHD using a propensity score to 2,062 matched patients on conventional dialysis [26]. These are the two largest studies on NIHD published to date; other published studies often lack control groups or only include a small number of patients [27-31] (Table 1). In addition, the parameters investigated differ widely among these studies. For example, depending on the study, blood pressure control was investigated and reported as systolic and/or diastolic pressure and/or left ventricular hypertrophy and/or dosage of antihypertensive medication. For such reasons a meta-analysis of all studies does not seem feasible.

\section{Phosphate control}

Ok et al. reported a significant reduction in serum phosphate levels in patients on NIHD $(3.87 \mathrm{mg} / \mathrm{dl})$ when compared with patients on conventional dialysis $(4.96 \mathrm{mg} / \mathrm{dl})$, despite a reduced number of patients who needed phosphate binders (22 vs. $83 \%$ ) [25]. In a second large study, serum phosphate levels were also significantly lower in patients on NIHD $(5 \mathrm{mg} / \mathrm{dl})$ than in those on conventional dialysis $(5.73 \mathrm{mg} / \mathrm{dl})$ [26]. In three of the five smaller studies, phosphate control (lower serum phosphate levels and/or lower amount of phosphate binders) improved [27, 29, 30], while no change was encountered in the remaining two studies [28, 31].

\section{Blood pressure control}

In a prospective, case-control study, Ok et al. found that predialytic blood pressure level was equal in both groups of patients but that patients on NIHD (8\%) needed antihypertensive medication less frequently than those on conventional dialysis $(22 \%)$ [25]. Left ventricular mass in patients on NIHD was significantly reduced (116 vs. $\left.139 \mathrm{~g} / \mathrm{m}^{2}\right)$ [25]. Lacson et al. reported on the lower predialytic systolic blood pressure levels of NIHD patients [150 vs. $147 \mathrm{mmHg}$ (controls)] [26]. In all smaller studies an improvement in blood pressure control (lower blood pressure and/or lower amounts of antihypertensive drugs and/or reduction of left ventricular mass) could be observed [27-31].

\section{Anemia control}

Ok et al. also observed that the time-averaged mean hemoglobin level in the NIHD group was higher than that in the conventional dialysis group (12 vs $11.7 \mathrm{~g} / \mathrm{dl}$ ) [25]. Additionally, the percentage of patients with erythropoietin therapy decreased from 56 to $25 \%$ in the NIHD group, while the erythropoietin use remained unchanged in the control group [25]. Lacon et al. reported an increase in hemoglobin levels in the NIHD group from 11.8 to $12.2 \mathrm{~g} / \mathrm{dl}$, while hemoglobin levels in the conventional dialysis group were stable [26]. In three smaller studies, anemia control (higher hemoglobin levels and/or lower erythropoietin doses) improved [27, 28, 30]; in one study no difference in anemia control was found [31].

Table 1 Studies on nocturnal home hemodialysis in adult dialysis patients

\begin{tabular}{|c|c|c|c|c|c|c|c|c|}
\hline Study & Study design & $n^{\mathrm{a}}$ & $\begin{array}{l}\text { Phosphate } \\
\text { control }\end{array}$ & $\begin{array}{l}\text { Blood } \\
\text { pressure } \\
\text { control }\end{array}$ & $\begin{array}{l}\text { Anemia } \\
\text { control }\end{array}$ & $\begin{array}{l}\text { Vascular access } \\
\text { complications }\end{array}$ & Quality of life & Mortality \\
\hline Ok et al. 2011 [25] & $\begin{array}{l}\text { Prospective } \\
\text { case-control }\end{array}$ & 247 & Improved & Improved & Improved & n.i. & $\begin{array}{l}\text { Constant (reduced } \\
\text { under CHD) }\end{array}$ & Reduced \\
\hline Lacson et al. 2012 [26] & $\begin{array}{l}\text { Retrospective } \\
\text { Propensity score } \\
\text { matching }\end{array}$ & 746 & Improved & Improved & Improved & n.i. & n.i. & Reduced \\
\hline Bugeja et al. 2009 [27] & $\begin{array}{l}\text { Retrospective } \\
\text { observational }\end{array}$ & 39 & Improved & Improved & Improved & n.i. & Improved & n.i. \\
\hline David et al. 2009 [28] & Prospective cohort & 13 & No difference & Improved & Improved & n.i. & n.i. & n.i. \\
\hline Troidle et al. 2007 [29] & $\begin{array}{l}\text { Retrospective } \\
\text { observational }\end{array}$ & 16 & Improved & Improved & n.i. & n.i. & Constant & n.i. \\
\hline Haag-Weber 2003 [30] & Prospective cohort & 9 & Improved & Improved & Improved & n.i. & Improved & n.i. \\
\hline McGregor 2001 [31] & $\begin{array}{l}\text { Prospective } \\
\text { cross-over }\end{array}$ & 9 & No difference & Improved & No difference & n.i. & $\begin{array}{l}2 \text { parts improved, } \\
2 \text { parts decreased }\end{array}$ & n.i. \\
\hline
\end{tabular}

CHD, Conventional hemodialysis; n.i., not investigated

${ }^{\text {a }}$ Number of patients on intensified dialysis 
Quality of life

Ok et al. measured the quality of life using the Medical Outcomes Study 36-item short form (SF-36) questionnaire and concluded that the quality of life remained stable in their patients on NIHD, while that in the control group deteriorated [25]. In the large retrospective study conducted by Lacson et al., the quality of life was not investigated [26]. In contrast, three of the smaller studies [27, 30,31] did report an improvement in the quality of life. For example, Bugeja et al. investigated the quality of life using a self-developed questionnaire and found that the quality of life improved after patients switched to NIHD [27]. Haag Weber et al. also reported an improved quality of life after patients switch to NIHD [30], but these authors did not report just how they measured the quality of life in their patients. Mc Gregor et al. investigated quality of life via the kidney disease quality of life $\left(\mathrm{KDQOL}_{\mathrm{TM}}\right)$ instrument [31]. Following their switch to NIHD, patients reported less uremia-related symptoms and less physical suffering but more inference with social activities and a greater burden on their families. In this study, NIHD was conducted at home, which may explain the burden on patient's families.

Troidle et al. reported no difference in quality of life (investigated via SF-36 questionnaire) [29]. However, time to resumption of usual activities was shorter after the patients started NIHD.

\section{Withdrawals}

Withdrawals were only investigated in the two larger studies. In the prospective study of Ok et al., 49 of 247 NIHD patients withdrew from the therapy because they felt uncomfortable with in-center NIHD [25]. Lacson et al. reported that among their active patients, 186 (42\%) were still on NIHD therapy after 2 years; in contrast, 1,185 patients (57\%) remained active among the conventional HD group [26].

\section{Mortality}

Mortality was investigated in the large, prospective study of Ok et al. [25]. In this study, 247 patients on in-center NIHD were matched with 247 patients on conventional dialysis. Overall mortality rate was significantly lower in those on NIHD (1.77 per 100 patient-years) than on conventional dialysis (6.23 per 100 patient-years). Mean followup was 11.3 months. Lacson et al. compared 746 NIHD patients retrospectively using a propensity score matching with 2062 conventional HD patients [26]. After 2 years, those patients on NIHD had a significantly lower overall mortality rate than those on conventional dialysis (19 vs. $27 \%$, respectively). Mortality was not investigated in the smaller studies.

\section{Advantage and disadvantage of NIHD in adults}

In this section we focus on the advantages and disadvantages of NIHD in comparison to those of other intensified modalities (SDHD and NHHD).

Only a few RCTs of intensified HD programs have been conducted. Most studies have been performed without a control group and with only a small number of participants. However, the intensified HD programs have been found to improve phosphate homeostasis, blood pressure control and anemia control. The same advantages have been shown in SDHD and NHHD [23, 24, 32].

Whether intensified dialysis programs improve a patient's quality of life is difficult to evaluate. Studies on NIHD have demonstrated a tendency towards an improved quality of life compared to conventional HD [25, 27, 30, 31]. However, both of the prospective studies conducted to date show that a considerable number of patients left the program (see section Withdrawals) $[25,26]$. Ok et al. commented that these patients felt uncomfortable with in-center NIHD [25].

The only RCT with patients on SDHD found that the quality of life improved compared to those on NIHD but that only $78 \%$ of the SDHD patients had more than five dialysis sessions per week [23]. Suri et al. found a poor long-term tolerability for SDHD [33]. In this large retrospective, study $30 \%$ of the patients on SDHD switched to conventional dialysis during the first year of therapy.

In one of the two RCTs on NHHD there was no difference in the quality of life between NHHD and conventional dialysis. In this study, only $25 \%$ of the patients with NHHD had more than five dialysis sessions per week [24]. In the other study on NHHD there was an improvement in a number of kidney-specific topics in the quality of life scores, while the whole quality of life remained unchanged [32]. In none of the studies on quality of life published to date were patients on intensified dialysis in worse condition than those on conventional dialysis.

Acceptance by the patients, especially of the daily intensified dialysis methods, is questioned by these findings. The efficacy of such intensified dialysis methods most certainly depends on the attitude of the individual patient. For the patient who might sleep well while maintaining dialysis, the quality of life will improve; to the contrary, the patient who cannot sleep on dialysis will quit the intensified program.

The question of whether intensified dialysis programs will provide longer survival for a patient is even harder to answer. In the pediatric and adolescent clinical setting only surrogate parameters like blood pressure, phosphate homeostasis or nutritional status can be evaluated. In a large number of published studies in adults, patients on in-center or home dialysis were not separately investigated, which may have resulted in a selection bias because home HD is associated 
with a survival advantage even when there is no difference between conventional or intensified dialysis modalities [34]. Patients with higher motivation, fewer co-morbidities and a stable social environment will prefer home dialysis to incenter dialysis. In the prospective, controlled trials performed to date, as well as in a number of the larger retrospective trials, intensified dialysis and conventional dialysis were performed at the same location, either at home or in the dialysis center [23-26, 33]. These studies will most likely be the best ones for investigating mortality rates. Patients on NIHD seem to have a lower mortality rate than those on conventional dialysis [25, 26]. In their RCT on NHHD, Rocco et al. found no difference in mortality between home NHHD and conventional home HD [24]. The results are more conflicting for SDHD: the FHN Trial Group conducted an RCT in which they investigated 120 patients on in-center HD versus 125 patients on SDHD. These authors reported that mortality was lower in those patients on SDHD [23]. In a large, retrospective study in which 318 SDHD patients were matched using the propensity score with 575 patients on conventional dialysis, the mortality rate was higher in patients on SDHD [33]. One reason for the higher mortality rate in patients on SDHD could be that daily dialysis was prescribed as a rescue therapy. Therefore, patients on SDHD could be more seriously ill than those maintained on conventional dialysis [33]. Other reasons for the higher mortality risk could be frequent exposure to the dialyzer, which may cause inflammation, or more frequent cannulation of the fistula, which may increase the risk of vascular access complications, potentially resulting in a greater use of catheters [33]. The greater risk of vascular access problems was also found in two RCTs in patients on daily $\operatorname{HD}[23,24]$.

NIHD is probably the best compromise between sufficient - but not too much - dialysis [35, 36]. There is also the advantage of sparing the blood access from frequent cannulation, as well as limiting frequent dialysis sessions. The burden of therapy with NIHD seems to be less than that in the daily modalities.

\section{Intensified dialysis programs for children and adolescents}

Intensified dialysis programs for children and adolescents have been established in very few centers worldwide [37-43] (Table 2).

SDHD in children and adolescents was initiated in Strassburg, France, as a daily in-center high-efficiency online HDF [40]. As in adults, positive effects of intensified dialysis were encountered in the pediatric patients. Serum phosphate levels decreased despite phosphate binders being reduced after the switch from HD to SDHD (1.87 vs. $1.28 \mathrm{mmol} / \mathrm{l})$ [40]. Patients on SDHD had neither fluid nor dietary restrictions. Antihypertensive medication was reduced on SDHD. Growth retardation, one of the major problems in children and adolescents with advanced stages of CKD, was significantly less on SDHD. In a second study, the research group showed that SDHD promotes catch-up growth in combination with growth hormone therapy [41], leading these authors to speculate that the improved response to recombinant human growth hormone is the result of less malnutrition and cachexia, De Camargo et al. reported on improved growth in children and adolescents on SDHD even without growth hormone therapy. In their prospective, observational study, $33 \%$ of the patients on SDHD showed a 0.5 standard deviation score (SDS) for height gain, whereas only $8 \%$ of the patients on conventional HD achieved the same level [43]. The quality of life in children and adolescents on SDHD is not currently being systematically investigated.

NHHD is mainly performed in countries such as Canada or Australia where distances to the next dialysis center are unacceptably long. Geary et al. established a NHHD program for children and adolescents in Canada [42]. Patients had no fluid or dietary restriction after switching to NHHD. Although quality of life was not systematically evaluated, the authors reported that the quality of life and school attendance improved after the patients switched to NHHD [42].

Table 2 Studies on intensified dialysis in children and adolescents

\begin{tabular}{|c|c|c|c|c|c|c|c|c|}
\hline Study & $\begin{array}{l}\text { Dialysis } \\
\text { modality }\end{array}$ & $n^{\mathrm{a}}$ & $\begin{array}{l}\text { Phosphate } \\
\text { control }\end{array}$ & $\begin{array}{l}\text { Blood pressure } \\
\text { control }\end{array}$ & Anemia control & Growth & $\begin{array}{l}\text { Days out } \\
\text { of school }\end{array}$ & Quality of life \\
\hline Fischbach et al. 2004 [40] & SDHD & 5 & Improved & improved & Improved? & Improved & Less & n.i. \\
\hline Fischbach et al. 2010 [41] & SDHD & 15 & n.i. & n.i. & n.i. & Improved & n.i. & n.i. \\
\hline De Camargo et al. 2014 [43] & SDHD & 24 & n.i. & n.i. & n.i. & Improved & n.i. & n.i. \\
\hline Hoppe et al. 2011 [38] & NIHD & 16 & Improved & Improved & Improved & n.i. & Less & Improved \\
\hline Thumfart et al. 2014 [45] & NIHD & 7 & Improved & Improved & n.i. & n.i. & n.i. & n.i. \\
\hline Geary et al. 2005 [42] & NHHD & 4 & Improved & No change & Improved? & n.i. & Less & Improved \\
\hline
\end{tabular}

SDHD short daily dialysis; NIHD nocturnal intermittent dialysis; NHHD nocturnal home dialysis

${ }^{\text {a }}$ Number of patients on intensified dialysis 


\section{Studies on children and adolescents on NIHD}

The concept of in-center NIHD in children and adolescents was established in Berlin, Germany, in 2005 [38]. In a first publication, 16 children and adolescents were prospectively investigated before and after switching from conventional HD to NIHD. Since then the program has been carried out as an prospective observational study [38].

In this group of children, serum phosphate levels decreased from 2.1 to $1.4 \mathrm{mmol} / \mathrm{l}$ after the switch to NIHD despite a reduction in the use of phosphate binders. Blood pressure control improved on NIHD: the predialytic mean arterial blood pressure declined from 102 to $93 \mathrm{mmHg}$, and antihypertensive medication could be reduced. Preexisting left ventricular hypertrophy, which was present in two patients when on HD, resolved on NIHD. Anemia control improved during the study. Hemoglobin levels rose from 10 to $11 \mathrm{~g} / \mathrm{dl}$ while erythropoietin dosage remained stable. Following the switch to NIHD, dietary and fluid restrictions could be lifted in every patient. Potassium binders could be reduced. The protein catabolic rate increased (from $1.2 \mathrm{~g} / \mathrm{kg}$ /day on conventional HD to $1.5 \mathrm{~g} / \mathrm{kg} /$ day on NIHD). The appetite of most patients improved. The quality of life was investigated with the SF-36 questionnaire. After 4 months on NIHD, the general wellbeing improved by $13 \%$, social efficiency by $22 \%$, psychosocial well-being by $11 \%$ and vitality by $12 \%$. Days absent from school declined from 37 days during the 6 months when the patient was on conventional dialysis to 12 days in 6 months after the switch to NIHD [38].

To further improve NIHD, HDF was implemented. Based on their clinical experience, Fischbach et al. reported that high-efficiency HDF also had beneficial effects in the pediatric setting [44]. Thumfart et al. combined NIHD with HDF (NHDF) in a prospective cross-over study [45] and found that serum phosphate concentration was significantly reduced in both intensive dialysis modalities, with NIHD lowering the phosphate concentration by $0.43 \mathrm{mg} / \mathrm{dl}$ and NHDF lowering it by $0.5 \mathrm{mg} / \mathrm{dl}$ despite the discontinuation of phosphate binders [45]. Predialytic mean arterial blood pressure was significantly reduced by $8 \mathrm{mmHg}$ in patients on NIHD or NHDF despite a reduction of antihypertensive medication. Dietary and fluid restrictions could be lifted in all patients irregardless of dialysis regimen (NIHD or NHDF). Albumin levels were significantly higher in the patients on NIHD and NHDF. There was no difference in the concentration of trace elements and vitamins in children on conventional HD, NIHD and NHDF. This finding is even more noteworthy because convective volume in the NHDF setting exceeded 301 . One logical explanation is that any losses were fully compensated due to increased appetite and improved nutritional status of the patients. The most important effects on patients in this study were attributed more to the switch of the patients from conventional HD to
NIHD than to the effects of HDF alone [45]. However, $\mathrm{Kt} / \mathrm{V}$ was even higher in children on NHDF than in those on NIHD. Therefore, HDF may be a promising treatment modality that allows further improvement of dialysis efficacy even in children treated with intensified dialysis.

\section{Practical aspects of NIHD in children and adolescents}

At our center, we started NIHD as a prospective observational study in 2005. To date, more than 20 patients, mainly adolescents, have been included in our NIHD program. The dialysis regimen consists of three 8-h sessions of NIHD per week (9 p.m. to 5 a.m.). Based on our experience, Monday, Wednesday and Friday are the most suitable days for the patients. With this scheduling of dialysis sessions, the patients are able to attend school two days per week after a dialysis session. To allow the patients some recovery, the nocturnal dialysis sessions start around 9:00 p.m. and are terminated around 5:00 a.m. Patients can therefore sleep up to 1$2 \mathrm{~h}$ without dialysis before getting up. NIHD is performed via a fistula or catheter. Fistulas are punctured using the rope-ladder technique by medical staff or by the patient him/herself. At the present time, conventional HD machines (e.g. Fresenius 5008H) are used with, if necessary, pediatric tubing systems. Heparin is used as an anticoagulant in all patients. If necessary, activated clotting time is regulated to between $150-180 \mathrm{~s}$ by altering the heparin dosage. Blood flow is set at a maximal possible flow. For NHDF, convective flow is set at one-third of the blood flow in the postdilution mode. We are currently using the Fresenius $5008 \mathrm{H}$ machine in the 'autosub+' mode. The composition of the dialysate (sodium, potassium and bicarbonate) is set after the initial electrolyte composition has been determined. The concentration of calcium in the dialysate is initially set at $1.75 \mathrm{mmol} / \mathrm{l}$ and adjusted, if necessary (Table 3). The care of the patients is realized by one specialized dialysis nurse for a maximum three patients.

Table 3 Practical aspects of NIHD in children and adolescents

\begin{tabular}{ll}
\hline Parameters & Settings \\
\hline Anticoagulant & Heparin (or others); ACT $150-180 \mathrm{~s}$ \\
Blood flow & $4-6 \mathrm{ml} / \mathrm{min} / \mathrm{kg}$ body weight \\
Dialysate flow & $500 \mathrm{ml} / \mathrm{min}$ \\
Dialysate & Set after initial electrolyte determination \\
& Calcium usually $1.75 \mathrm{mmol} / 1$ \\
Time & $8 \mathrm{~h}$ \\
\hline
\end{tabular}

$A C T$ activated clotting time, NIHD nocturnal intermittent hemodialysis 
Medical supervision is performed by a pediatrician specialized in pediatric nephrology.

\section{Advantages and disadvantages of NIHD in children and adolescents}

Intensified dialysis programs are an efficient modality to improve intermediate outcomes in dialysis patients. Especially in children and adolescents, in whom the morbidity and mortality are extremely high in comparison with the age-adjusted general population, the best dialysis option should be offered.

Advances in SDHD have resulted in a protocol where the patients can be seen by the medical staff every day but can sleep at home, which is very important for younger children. For older children and adolescents, social rehabilitation in school or the job-related environment can be difficult on SDHD.

NIHD programs are probably the best compromise between more but not too much dialysis. Especially in urban areas, NIHD can be performed in-center which may lower the burden of care, as in NHHD, on the patient's family. Dialysis overnight might offer the patient the whole daytime for school, work and free time. Our patients usually have no problems with the sleep disturbances during nightly dialysis sessions that have been reported in adults. Up to now, only one patient has quit our program due to insufficient sleep.

NIHD needs a team effort that involves physicians, nurses, social workers, psychologists and dietitians. The nurses in particular have to accept extended working times and work night shifts.

One problem of the NIHD program is the funding by health insurance companies. All intensified dialysis programs are rather expensive during childhood, as children are much more demanding on dialysis relative to adults. Therefore, one specialized dialysis nurse takes care of a maximum of three patients. Such programs require additional financial resources. Currently, for nocturnal dialysis programs the dialysis center is reimbursed for only one "conventional" day, while SDHD receives financing every single day. However, the higher costs of intensified dialysis could ultimately be offset - even surpassed - by future earnings. That patients, especially those on NIHD, can attend more school implies that they might in the future, due to their better education, contribute to social welfare systems rather than being dependent their entire lives on such systems.

\section{Conclusion}

Intensified dialysis programs are a promising option which should be reconsidered in every dialysis patient. The beneficial effects of intensified programs raise the question of whether such programs should become the standard and not the exception.

\section{Summary points}

Intensified programs:

- $\quad$ are feasible in children and adolescents;

- reduce medication prescription and dietary restrictions

- reduce uremia-associated comorbidities, such as hyperphosphatemia, anemia and arterial hypertension;

- allow, in the form of NIHD, school attendance;

- increase the quality of life in most of the patients.

\section{Multiple choice questions (answers are provided following the reference list)}

1: The term intensified dialysis refers to:
A. Increasing blood flow
B. Increasing dialysate flow
C. More visits of the patients by staff
D. Increasing time on dialysis

2: Average single pool $\mathrm{Kt} / \mathrm{V}$ in intensified programs is:
A. $1.8-4.3$
B. $4.5-9.0$
C. never higher than 6.0
D. $3.5-5.8$

3: In intensified HD programs, phosphate control is on average:
A. better than on conventional HD
B. unchanged compared to conventional HD because of the increased nutritional status
C. dramatically improved, if HDF is added
D. age dependent

4: To optimize HD the most promising approach is:
A. double time on dialysis
B. add HDF
C. optimizing blood flow
D. using high flux filters and increasing dialysate flow

5: In adult patients complications of vascular access on SDHD are:
A. reduced in comparison to conventional HD
B. increased in comparison to conventional HD
C. unchanged in comparison to conventional HD
D. have not been investigated 


\section{References}

1. Rahmel A (ed) (2013) Eurotransplant annual report 2012. Eurotransplant International Foundation, Leiden. Available at: www.eurotransplant.org

2. Foley RN, Parfrey PS, Sarnak MJ (1998) Epidemiology of cardiovascular disease in chronic renal disease. J Am Soc Nephrol 9:S16-S23

3. Groothoff JW (2005) Long-term outcomes of children with end-stage renal disease. Pediatr Nephrol 20:849-853

4. Kramer A, Stel VS, Tizard J, Verrina E, Rönnholm K, Pálsson R, Maxwell H, Jager KJ (2009) Characteristics and survival of young adults who started renal replacement therapy during childhood. Nephrol Dial Transplant Assoc 24:926-933

5. Mitsnefes MM (2012) Cardiovascular disease in children with chronic kidney disease. J Am Soc Nephrol 23:578-585

6. Oh J, Wunsch R, Turzer M, Bahner M, Raggi P, Querfeld U, Mehls $\mathrm{O}$, Schaefer F (2002) Advanced coronary and carotid arteriopathy in young adults with childhood-onset chronic renal failure. Circulation 106:100-105

7. Brancaccio D, Bellasi A, Cozzolino M, Galassi A, Gallieni M (2009) Arterial accelerated aging in dialysis patients: the clinical impact of vascular calcification. Curr Vasc Pharmacol 7:374-380

8. Moe SM, Drüeke T, Lameire N, Eknoyan G (2007) Chronic kidney disease-mineral-bone disorder: a new paradigm. Adv Chron Kidney Dis 14:3-12

9. Ikizler TA (2013) Optimal nutrition in hemodialysis patients. Adv Chron Kidney Dis 20:181-189

10. Shroff R, Quinlan C, Mitsnefes M (2011) Uraemic vasculopathy in children with chronic kidney disease: prevention or damage limitation? Pediatr Nephrol 26:853-865

11. Fischbach M, Fothergill H, Seuge L, Zaloszyc A (2011) Dialysis strategies to improve growth in children with chronic kidney disease. J Ren Nutr 21:43-46

12. Tjaden L, Tong A, Henning P, Groothoff J, Craig JC (2012) Children's experiences of dialysis: a systematic review of qualitative studies. Arch Dis Child 97:395-402

13. Eknoyan G, Beck GJ, Cheung AK, Daugirdas JT, Greene T, Kusek JW, Allon M, Bailey J, Delmez JA, Depner TA, Dwyer JT, Levey AS, Levin NW, Milford E, Ornt DB, Rocco MV, Schulman G, Schwab SJ, Teehan BP, Toto R, Hemodialysis (HEMO) Study Group (2002) Effect of dialysis dose and membrane flux in maintenance hemodialysis. N Engl J Med 347:2010-2019

14. Paniagua R, Amato D, Vonesh E, Correa-Rotter R, Ramos A, Moran J, Mujais S, Mexican Nephrology Collaborative Study Group (2002) Effects of increased peritoneal clearances on mortality rates in peritoneal dialysis: ADEMEX, a prospective, randomized, controlled trial. J Am Soc Nephrol 13:1307-1320

15. Grooteman MP, van den Dorpel MA, Bots ML, Penne EL, van der Weerd NC, Mazairac AH, den Hoedt $\mathrm{CH}$, van der Tweel I, Lévesque R, Nubé MJ, ter Wee PM, Blankestijn PJ, Investigators CONTRAST (2012) Effect of online hemodiafiltration on all-cause mortality and cardiovascular outcomes. J Am Soc Nephrol 23:1087-1096

16. Ok E, Asci G, Toz H, Ok ES, Kircelli F, Yilmaz M, Hur E, Demirci MS, Demirci C, Duman S, Basci A, Adam SM, Isik IO, Zengin M, Suleymanlar G, Yilmaz ME, Ozkahya M, Turkish Online Haemodiafiltration Study (2013) Mortality and cardiovascular events in online haemodiafiltration (OL-HDF) compared with high-flux dialysis: results from the Turkish OL-HDF Study. Nephrol Dial Transplant 28:192-202

17. Maduell F, Moreso F, Pons M, Ramos R, Mora-Macià J, Carreras J, Soler J, Torres F, Campistol JM, Martinez-Castelao A, ESHOL Study Group (2013) High-efficiency postdilution online hemodiafiltration reduces all-cause mortality in hemodialysis patients. J Am Soc Nephrol 24:487-497
18. Canaud B, Bragg-Gresham JL, Marshall MR, Desmeules S, Gillespie BW, Depner T, Klassen P, Port FK (2006) Mortality risk for patients receiving hemodiafiltration versus hemodialysis: European results from the DOPPS. Kidney Int 69:2087-2093

19. Charra B, Calemard E, Cuche M, Laurent G (1983) Control of hypertension and prolonged survival on maintenance hemodialysis. Nephron 33:96-99

20. Lindsay RM, Suri RS, Moist LM, Garg AX, Cuerden M, Langford S, Hakim R, Ofsthun NJ, McDonald SP, Hawley C, Caskey FJ, Couchoud C, Awaraji C, Nesrallah GE (2011) International quotidian dialysis registry: Annual report 2010. Hemodial Int. doi:10.1111/j. 1542-4758.2010.00521.x

21. McFarlane PA (2009) More of the same: improving outcomes through intensive hemodialysis. Semin Dial 22:598-602

22. Movilli E, Gaggia P, Zubani R, Camerini C, Vizzardi V, Parrinello G, Savoldi S, Fischer MS, Londrino F, Cancarini G (2007) Association between high ultrafiltration rates and mortality in uraemic patients on regular haemodialysis. A 5-year prospective observational multicentre study. Nephrol Dial Transplant 22:3547-3552

23. FHN Trial Group, Chertow GM, Levin NW, Beck GJ, Depner TA, Eggers PW, Gassman JJ, Gorodetskaya I, Greene T, James S, Larive B, Lindsay RM, Mehta RL, Miller B, Ornt DB, Rajagopalan S, Rastogi A, Rocco MV, Schiller B, Sergeyeva O, Schulman G, Ting GO, Unruh ML, Star RA, Kliger AS (2010) In-center hemodialysis six times per week versus three times per week. N Engl J Med 363: 2287-2300

24. Rocco MV, Lockridge RS Jr, Beck GJ, Eggers PW, Gassman JJ, Greene T, Larive B, Chan CT, Chertow GM, Copland M, Hoy CD, Lindsay RM, Levin NW, Ornt DB, Pierratos A, Pipkin MF, Rajagopalan S, Stokes JB, Unruh ML, Star RA, Kliger AS, Frequent Hemodialysis Network (FHN) Trial Group, Kliger A, Eggers P, Briggs J, Hostetter T, Narva A, Star R, Augustine B, Mohr P, Beck G, Fu Z, Gassman J, Greene T, Daugirdas J, Hunsicker L, Larive B, Li M, Mackrell J, Wiggins K, Sherer S, Weiss B, Rajagopalan S, Sanz J, Dellagrottaglie S, Kariisa M, Tran T, West J, Unruh M, Keene R, Schlarb J, Chan C, McGrath-Chong M, Frome R, Higgins H, Ke S, Mandaci O, Owens C, Snell C, Eknoyan G, Appel L, Cheung A, Derse A, Kramer C, Geller N, Grimm R, Henderson L, Prichard S, Roecker E, Rocco M, Miller B, Riley J, Schuessler R, Lockridge R, Pipkin M, Peterson C, Hoy C, Fensterer A, Steigerwald D, Stokes J, Somers D, Hilkin A, Lilli K, Wallace W, Franzwa B, Waterman E, Chan C, McGrath-Chong M, Copland M, Levin A, Sioson L, Cabezon E, Kwan S, Roger D, Lindsay R, Suri R, Champagne J, Bullas R, Garg A, Mazzorato A, Spanner E, Rocco M, Burkart J, Moossavi S, Mauck V, Kaufman T, Pierratos A, Chan W, Regozo K, Kwok S (2011) The effects of frequent nocturnal home hemodialysis: the Frequent Hemodialysis Network Nocturnal Trial. Kidney Int 80:1080-1091

25. Ok E, Duman S, Asci G, Tumuklu M, Onen Sertoz O, Kayikcioglu M, Toz H, Adam SM, Yilmaz M, Tonbul HZ, Ozkahya M, Long Dialysis Study Group (2011) Comparison of 4- and 8-h dialysis sessions in thrice-weekly in-centre haemodialysis: a prospective, case-controlled study. Nephrol Dial Transplant 26:1287-1296

26. Lacson E Jr, Xu J, Suri RS, Nesrallah G, Lindsay R, Garg AX, Lester K, Ofsthun N, Lazarus M, Hakim RM (2012) Survival with threetimes weekly in-center nocturnal versus conventional hemodialysis. J Am Soc Nephrol 23:687-695

27. Bugeja A, Dacouris N, Thomas A, Marticorena R, McFarlane P, Donnelly S, Goldstein M (2009) In-center nocturnal hemodialysis: another option in the management of chronic kidney disease. Clin J Am Soc Nephrol 4:778-783

28. David S, Kümpers P, Eisenbach GM, Haller H, Kielstein JT (2009) Prospective evaluation of an in-centre conversion from conventional haemodialysis to an intensified nocturnal strategy. Nephrol Dial Transplant 24:2232-2240 
29. Troidle L, Hotchkiss M, Finkelstein F (2007) A thrice weekly incenter nocturnal hemodialysis program. Adv Chron Kidney Dis 14: 244-248

30. Haag-Weber M (2003) Treatment options to intensify hemodialysis. Kidney Blood Press Res 26:90-95

31. McGregor DO, Buttimore AL, Lynn KL, Nicholls MG, Jardine DL (2001) A Comparative Study of Blood Pressure Control with Short In-Center versus Long Home Hemodialysis. Blood Purif 19:293-300

32. Culleton BF, Walsh M, Klarenbach SW, Mortis G, Scott-Douglas N, Quinn RR, Tonelli M, Donnelly S, Friedrich MG, Kumar A, Mahallati H, Hemmelgarn BR, Manns BJ (2007) Effect of frequent nocturnal hemodialysis vs conventional hemodialysis on left ventricular mass and quality of life: a randomized controlled trial. J Am Med Assoc 298:1291-1299

33. Suri RS, Lindsay RM, Bieber BA, Pisoni RL, Garg AX, Austin PC, Moist LM, Robinson BM, Gillespie BW, Couchoud CG, Galland R, Lacson EK Jr, Zimmerman DL, Li Y, Nesrallah GE (2013) A multinational cohort study of in-center daily hemodialysis and patient survival. Kidney Int 83:300-307

34. Marshall MR, Hawley CM, Kerr PG, Polkinghorne KR, Marshall RJ, Agar JW, McDonald SP (2011) Home hemodialysis and mortality risk in Australian and New Zealand populations. Am J Kidney Dis 58:782-793

35. Chazot C, Ok E, Lacson E Jr, Kerr PG, Jean G, Misra M (2013) Thrice-weekly nocturnal hemodialysis: the overlooked alternative to improve patient outcomes. Nephrol Dial Transplant 28:2447-2455

36. Hakim RM, Saha S (2014) Dialysis frequency versus dialysis time, that is the question. Kidney Int 85:1024-1029

37. Müller D, Zimmering M, Chan CT, McFarlane PA, Pierratos A, Querfeld U (2008) Intensified hemodialysis regimens: neglected treatment options for children and adolescents. Pediatr Nephrol 23: $1729-1736$

38. Hoppe A, von Puttkamer C, Linke U, Kahler C, Booss M, Braunauer-Kolberg R, Hofmann K, Joachimsky P, Hirte I, Schley S, Utsch B, Thumfart J, Briese S, Gellermann J,
Zimmering M, Querfeld U, Müller D (2011) A hospitalbased intermittent nocturnal hemodialysis program for children and adolescents. J Pediatr 158:95-99, 99.e1.

39. Fischbach M, Dheu C, Seuge L, Menouer S, Terzic J (2008) In-center daily on-line hemodiafiltration: a 4-year experience in children. Clin Nephrol 69:279-284

40. Fischbach M, Terzic J, Laugel V, Dheu C, Menouer S, Helms P, Livolsi A (2004) Daily on-line haemodiafiltration: a pilot trial in children. Nephrol Dial Transplant 19:2360-2367

41. Fischbach M, Terzic J, Menouer S, Dheu C, Seuge L, Zalosczic A (2010) Daily on line haemodiafiltration promotes catch-up growth in children on chronic dialysis. Nephrol Dial Transplant 25:867-873

42. Geary DF, Piva E, Tyrrell J, Gajaria MJ, Picone G, Keating LE, Harvey EA (2005) Home nocturnal hemodialysis in children. J Pediatr 147:383-387

43. De Camargo MFC, Henriques CL, Vieira S, Komi S, Leão ER, Nogueira PC (2014) Growth of children with end-stage renal disease undergoing daily hemodialysis. Pediatr Nephrol 29:439-444

44. Fischbach M, Fothergill H, Zaloszyc A, Seuge L (2012) Hemodiafiltration: the addition of convective flow to hemodialysis. Pediatr Nephrol 27:351-356

45. Thumfart J, von Puttkamer C, Wagner S, Querfeld U, Müller D (2014) Hemodiafiltration in a pediatric nocturnal dialysis program. Pediatr Nephrol. doi:10.1007/s00467-014-2776-9

\section{Answers}

1. D
2. B
3. A
4. A
5. B 